Subscriber access provided by Lib4RI - Library for Eawag, Empa, PSI \& WSL

\title{
Article
}

\section{Improving the stability of amino-containing plasma polymer films in aqueous environments}

Johanna Dorst, Marianne Vandenbossche, Martin Amberg, Laetitia Bernard, Patrick Rupper, Klaus-Dieter Weltmann, Katja Fricke, and Dirk Hegemann

Langmuir, Just Accepted Manuscript • DOI: 10.1021/acs.langmuir.7b02135 • Publication Date (Web): 18 Sep 2017

Downloaded from http://pubs.acs.org on September 28, 2017

\section{Just Accepted}

"Just Accepted" manuscripts have been peer-reviewed and accepted for publication. They are posted online prior to technical editing, formatting for publication and author proofing. The American Chemical Society provides "Just Accepted" as a free service to the research community to expedite the dissemination of scientific material as soon as possible after acceptance. "Just Accepted" manuscripts appear in full in PDF format accompanied by an HTML abstract. "Just Accepted" manuscripts have been fully peer reviewed, but should not be considered the official version of record. They are accessible to all readers and citable by the Digital Object Identifier (DOI®). "Just Accepted" is an optional service offered to authors. Therefore, the "Just Accepted" Web site may not include all articles that will be published in the journal. After a manuscript is technically edited and formatted, it will be removed from the "Just Accepted" Web site and published as an ASAP article. Note that technical editing may introduce minor changes to the manuscript text and/or graphics which could affect content, and all legal disclaimers and ethical guidelines that apply to the journal pertain. ACS cannot be held responsible for errors or consequences arising from the use of information contained in these "Just Accepted" manuscripts. 


\title{
Improving the stability of amino-containing plasma
}

\section{polymer films in aqueous environments}

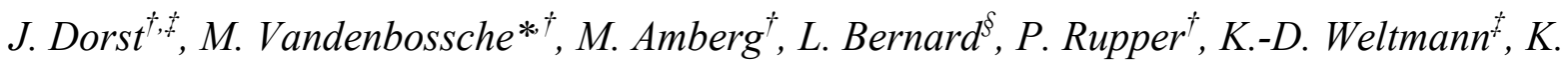 \\ Fricke $^{\dagger}$, D. Hegemann ${ }^{\dagger}$ \\ ${ }^{\dagger}$ Empa, Swiss Federal Laboratories for Materials Science and Technology, Lerchenfeldstrasse 5, \\ 9014 St. Gallen, Switzerland \\ $\$$ Leibniz Institute for Plasma Science and Technology (INP Greifswald e.V.), Felix-Hausdorff- \\ Str. 2, 17489 Greifswald, Germany \\ ${ }^{\S}$ Empa, Swiss Federal Laboratories for Materials Science and Technology, Überlandstrasse 129, \\ 8600 Dübendorf, Switzerland
}




\begin{abstract}
Plasma polymer films that contain amine groups ( $\mathrm{NH}_{2}$-PPFs) are known to degrade over time, particularly in aqueous environments. To reduce such aging effects, a vertical chemical gradient regarding the amine group density was explored ranging over a few nanometers at the coating surface. The gradient-containing nanofilms were formed in low pressure plasma by tuning plasma conditions while keeping the plasma "switched on". The coating process started with a more cross-linked $\mathrm{NH}_{2}$-PPF $\left(70 \mathrm{~W}, \mathrm{NH}_{3} / \mathrm{C}_{2} \mathrm{H}_{4} 4: 7\right.$ ), followed by the deposition of a few nanometers of a less cross-linked yet more functional $\mathrm{NH}_{2}-\mathrm{PPF}\left(50 \mathrm{~W}, \mathrm{NH}_{3} / \mathrm{C}_{2} \mathrm{H}_{4}\right.$ 7:7). Characterization of the prepared gradient coatings showed that the chemical composition depends on the $\mathrm{NH}_{3} / \mathrm{C}_{2} \mathrm{H}_{4}$ gas flow ratio, as observed by different analytical methods: plasma diagnostics during deposition and depth profiling analyses of the deposited coating. Finally, surface chemistry was analyzed during air and water aging, showing similar aging process of the $\mathrm{NH}_{2}$-PPF single layer and $\mathrm{NH}_{2}$-PPF with vertical chemical gradient in air, while the stability of the gradient coating was found to be enhanced in aqueous conditions maintaining the $\left[\mathrm{NH}_{2}\right] /[\mathrm{C}]$ amount of $\sim 1 \%$.
\end{abstract}

\author{
KEYWORDS \\ Plasma polymer nanofilms, vertical chemical gradient, depth profiling, plasma diagnostics, \\ oxidation
}




\section{Introduction}

During the last decades, a growing interest in using amino-containing plasma polymer films $\left(\mathrm{NH}_{2}\right.$-PPFs) for various applications in the biomedical field (e.g. bio-sensing, tissue engineering, cell culture) was observed. ${ }^{1-5}$ However, $\mathrm{NH}_{2}$-PPFs are not suitable for direct or long-term use due to their low stability in air involving chemical reactions ${ }^{6,7}$ and also in aqueous environments revealing thickness loss. ${ }^{8,9}$ Therefore, $\mathrm{NH}_{2}$-PPFs are typically used after stabilization, e.g. after immersion for a certain period in phosphate-buffered saline (PBS), ${ }^{1}$ however, resulting in a largely unknown surface composition. Thus, strategies to provide initially more stable $\mathrm{NH}_{2}$-PPFs become necessary. ${ }^{10}$

Instability of a PPF is related to strong aging effects leading to physicochemical modifications at the surface and/or in the bulk of the PPF. Thus, a non-stable film loses its chemical and mechanical properties over time, due to a change in surface functionality or degree of crosslinking, for example.

Three main phenomena are responsible for the strong aging effects: the hydrophobic recovery, the post-plasma oxidation process, and the film loss when stored in aqueous environments. Hydrophobic recovery is due to the restructuring of polar groups at the surface of the coating. Indeed, polar groups are turning towards the bulk of the coating to decrease the surface energy: on one hand, interfacial energy differences between the PPF and its environment imply a decrease in surface density of functional groups by adaption of the interfacial chemistry of the $\mathrm{PPF} ;$; 11 on the other hand, translational entropy of the system increases yielding a "dilution" of functionality at the surface of the coating by orienting the functional groups toward the bulk of the polymer film. ${ }^{11}$ Thus, hydrophobic recovery leads to a reduction of the number of available 
amine groups. ${ }^{12-15}$ Post-plasma oxidation which occurs preferably at the carbon atoms bonded to nitrogen atoms ${ }^{16,17}$ leads to a decrease of the number of amino groups at the surface of the coating, e.g. primary amine groups end up in amide groups after prolonged aging times. Film loss, or dissolution of low molecular weight fragments (or oligomers), of the PPF in aqueous environments occurs due to possible hydrolysis reactions, yielding loss of fragments that contain amine groups and ongoing oxidation of the PPF. ${ }^{8,17-21}$

Improvement of the stability of the PPF can be achieved by selecting deposition conditions leading to highly cross-linked PPFs: these PPFs can be stable for a long time in air and in water, but contain a very low number of functional groups, ${ }^{22}$ and are thus less suitable for bio-sensing applications, for example. ${ }^{23}$ Indeed, during plasma deposition, two processes occur, i.e. gas phase and surface reaction processes, leading to film-forming species that travel and deposit at the surface of the substrate, and ion bombardment that enhance the stability of the film by increasing cross-linking while reducing its functionality. Studies carried out in a plasma comprising a mixture of ethylene and ammonia showed that increasing stability, especially in aqueous media, is clearly at the expense of the $\left[\mathrm{NH}_{2}\right] /[\mathrm{C}]$ ratio (measured by XPS): a maximum of $\sim 2 \%$ was found by avoiding distinct film loss (when immersed over a few hours in water). 1,8,17,24,25 Therefore, the common method used to deposit PPFs, and $\mathrm{NH}_{2}-\mathrm{PPFs}$, presents severe limitations as cross-linking and functionalization cannot be tuned separately.

Recently, some studies were carried out to show that a well-defined vertical chemical gradient through the coating can enhance the stability in air and in water of PPFs. ${ }^{10,26-28}$ Vertical chemical gradients are coatings made of (at least) two superposed layers (for example, L and L'), which have different properties (degree of cross-linking, chemical composition, number of 
functional groups, wettability...), separated by a thin transition layer, allowing a gradual transition from L-layer properties to L'-layer properties, namely the vertical gradient.

In this study, $\mathrm{NH}_{2}$-PPFs with vertical chemical gradients were developed: a more cross-linked base layer was deposited onto the substrate to ensure high stability of the gradient, and, then, plasma conditions were tuned during deposition in order to deposit a more functional plasma polymer film on the top. Plasma chemistry was analyzed while changing deposition conditions, and $\mathrm{NH}_{2}$-PPFs with vertical chemical gradients were extensively characterized i) to prove that a vertical gradient is obtained, and ii) to give first explanations about the mechanisms implied in the formation of the vertical gradient. Finally, surface wettability and chemical composition were analyzed over time to provide first hints regarding the behavior of the $\mathrm{NH}_{2}$-PPF with vertical chemical gradients during air and water aging. Note that this study aims for the possibility to increase the life-time of amine-containing PPFs with defined surface composition in water, while hydrophobic recovery is less discussed. Anyway, it was already shown in a previous study that a vertical gradient structure in a PPF allows reducing hydrophobic recovery during air storage due to limited mobility in the near-surface layer. ${ }^{26}$

\section{Experimental section}

\section{Deposition of $\mathrm{NH}_{2}-\mathrm{PPF}$ with a vertical chemical gradient}

To prepare single layer coatings and PPFs with a vertical chemical gradient, a capacitively coupled low pressure discharge with 13.56 MHz radiofrequency (RF) excitation was used. As already described in previous papers, ${ }^{18,29}$ the cylindrical plasma reactor in the symmetrical 
configuration consists of two plane parallel electrodes $(30 \mathrm{~cm}$ in diameter) separated by a glass ring $(5 \mathrm{~cm}$ height). The upper electrode contains a gas showerhead, while the chamber is pumped via a grid through the lower electrode which is coupled to the RF generator enabling welldefined deposition conditions. ${ }^{29}$ Most of all, the matching was set to enable well-matched conditions right from the start of the plasma polymerization process as also during gradient formation.

Before depositing plasma polymer films, substrates (glass slides and Si-wafers) and reactor walls were cleaned in Ar plasma $(50 \mathrm{~W}, 10 \mathrm{~Pa}, 10 \mathrm{~min})$ to provide constant initial growth conditions. Then, a discharge was carried out in a mixture of $\mathrm{C}_{2} \mathrm{H}_{4}$ and $\mathrm{NH}_{3}$ in order to prepare the $\mathrm{NH}_{2}$ PPFs. To determine suitable deposition conditions for the more cross-linked plasma polymer film, an experimental series was prepared by varying the power from 10 to $150 \mathrm{~W}$ at a constant flow rate of 7 and $4 \mathrm{sccm}$ for $\mathrm{C}_{2} \mathrm{H}_{4}$ and $\mathrm{NH}_{3}$, respectively, and a constant pressure of $10 \mathrm{~Pa}$. A less cross-linked and more functional plasma polymer film was prepared according to the following deposition conditions: constant gas flow rate of $7 \mathrm{sccm}$ for $\mathrm{C}_{2} \mathrm{H}_{4}$ and $\mathrm{NH}_{3}(1: 1)$, constant pressure of $10 \mathrm{~Pa}$, and power input set to $50 \mathrm{~W}$; hereafter, the coating deposited under these conditions is labeled as "C-coating" (Table 1 and Figure 1). This coating was selected as a reasonable compromise of functionality vs. stability, with $\left[\mathrm{NH}_{2}\right] /[\mathrm{C}]=2.1 \%$ and $\left[\mathrm{NH}_{2}\right] /[\mathrm{N}]=10.8 \%$ as investigated in previous studies. ${ }^{23,25}$

\section{Investigation on chemical reactions in the plasma zone}

During plasma deposition at low pressure conditions, activation and dissociation occur by electron impact of the monomer, and also of the reactive gas, in the plasma zone. Formation of excited species $\left(\mathrm{M}^{*}\right)$ results in a first step (eq.(1)) that is followed by relaxation of these excited 
species to a lower energy state $(\mathrm{M})$ releasing a photon of energy equal to the difference between the two energy states (eq.(2)). ${ }^{30,31}$

$$
\begin{gathered}
\mathrm{M}+\mathrm{e}^{-} \rightarrow \mathrm{M}^{*}+\mathrm{e}^{-} \\
\mathrm{M}^{*} \rightarrow \mathrm{M}+\mathrm{h} v
\end{gathered}
$$

where $\mathrm{h}$ is the Planck constant and $v$ is the frequency of the emitted photon.

\section{Quasi-Arrhenius approach}

These reactions depend on the energy invested per particle in the gas phase, which is proportional to the external parameters power input per monomer gas flow rate $\mathrm{W} / \mathrm{F}_{\mathrm{m}}$ (for the examined plasma reactor). ${ }^{23,32}$ Thanks to these reactions, film-forming species are produced in the plasma zone and can travel in the reactor to be deposited onto the substrate. Assuming that the activation of the molecules in the plasma zone is the rate-limiting step in the film growth process, a quasi-Arrhenius equation (eq.(3)) can then be used to describe the specific plasma chemical reaction pathway (with a specific activation energy $\mathrm{E}_{\mathrm{a}}$ ) by plotting the mass deposition rate $R_{m}$ per monomer gas flow $F_{m}$ as a function of the specific energy input $W / F_{m}$ :

$$
\frac{R_{m}}{F_{m}}=G \exp \left(-\frac{E_{a}}{W / F_{m}}\right)
$$

where $\mathrm{G}$ is a reactor and process dependent factor related to the maximum monomer conversion into the film growth (and thus the electron energy distribution function). ${ }^{33,34}$ To measure $\mathrm{R}_{\mathrm{m}}$, plasma deposition was carried out onto glass slides, which mass was measured before and after deposition (balance Mettler Toledo XS204 deltarange, precision $\pm 0.1 \mathrm{mg}$ ). Note that the 
thickness of the coating was measured onto coated Si wafers by profilometry (profilometer Veeco Dektak 150), allowing the determination of the film density.

\section{Optical Emission Spectroscopy}

This quasi-Arrhenius approach helps to observe whether the same chemical reaction pathway occurs at different plasma deposition conditions, but does not identify clearly the chemical species present in the plasma zone. Thus, optical emission spectroscopy (OES) (AvaSpecULS2048-USB2, Avantes) method was used to collect the radiation coming from the plasma as it is possible to identify precisely (stable) excited species present in the plasma zone due to the specific frequencies emitted..$^{30,35}$ The spectra were taken over a wavelength range of 280-800 nm, averaged over three measurements, and analyzed by AvaSoft-Full software version 7.6.1 (Avantes).

\section{Characterization of the vertical chemical gradients}

Quartz crystal microbalance

A quartz crystal microbalance (QCM, Inficon) was installed inside the plasma reactor onto the upper, grounded electrode. The sensor, i.e. a silver-coated quartz crystal (Inficon), vibrated at a frequency of $6 \mathrm{MHz}$. The deposition of a PPF changed the mass, and thus the vibration frequency of the sensor. The input of the film density in the QCM device provided the thickness of the PPF during deposition; thus, deposition rate could readily be determined during the process. $^{36}$ The QCM device was used during the deposition of the vertical chemical gradient to discriminate the different coatings due to their different deposition rates, and to observe any change that might happen while tuning the deposition conditions (power and gas flow ratio). 
XPS-depth profiling

To characterize the vertical chemical gradients, depth profiling analyses were firstly carried out thanks to X-ray photoelectron spectrometry (XPS) to determine the atomic percentage of the elements contained in different layer depths. Depth profiling was conducted by means of the Kratos Gas Cluster Ion Source (GCIS) using $\mathrm{Ar}_{\mathrm{n}}{ }^{+}$cluster ion beams of $10 \mathrm{keV}$ and a cluster size of $\mathrm{n}=1000\left(\sim 10 \mathrm{eV}\right.$ nucleon $\left.{ }^{-1}\right)$. The ion incidence angle was $50^{\circ}$ and the take-off angle $90^{\circ}$. The crater size was $1 \mathrm{~mm} \times 1 \mathrm{~mm}$ with an analysis area of $110 \mu \mathrm{m}$ diameter in the center of each crater.

During depth profiling the elemental composition of the coatings was analyzed ex-situ with Xray photoelectron spectroscopy (XPS), an Axis Supra spectrometer (Kratos, Manchester, UK) utilizing monochromatic aluminum $\mathrm{K}_{\alpha}$ irradiation at $1486.6 \mathrm{eV}$. Charge neutralization was implemented by low energy electrons injected in the magnetic field of the lens from a filament located directly atop the sample. The spot size was $110 \mu \mathrm{m}$ in diameter. Survey scans $(0$ $1200 \mathrm{eV}$ ) and element spectra were recorded at a pass energy of $80 \mathrm{eV}$ for the estimation of the chemical element composition. Data acquisition and processing were carried out using the software CasaXPS, version 2.3.15 (Casa Software Ltd.). All values are given in XPS atomic percent.

In addition, quantification of the $\left[\mathrm{NH}_{2}\right] /[\mathrm{C}]$ amount at the surface of the $\mathrm{NH}_{2}$-PPFs was carried out using derivatization with 4-(trifluoromethyl)benzaldehyde (TFBA, Aldrich, $98 \%$ ) vapor at $45^{\circ} \mathrm{C}$ during 3 h. ${ }^{7,25}$ 
ToF-SIMS - depth profiling

Time-of-flight secondary ion mass spectrometry (ToF-SIMS, TOFSIMS.5, Iontof) was also used to identify the main molecular fragments through the thickness of the $\mathrm{NH}_{2}-\mathrm{PPFs}$, and to determine the molecular composition of the transition layer within the vertical chemical gradient. $25 \mathrm{keV} \mathrm{Bi}_{3}{ }^{+}$primary ions in the high mass resolution mode $(\mathrm{M} / \Delta \mathrm{M} \approx 5000)$ were used. All elements and molecular fragments from mass 1 to mass 512 Dalton were analyzed in parallel, on areas of $100 \times 100 \mu \mathrm{m}^{2}$ to ensure statistically relevant results. To reveal the depth profile through the vertical chemical gradient, a $250 \mathrm{eV} \mathrm{Cs}^{+}$sputtering beam was used in combination with the $\mathrm{Bi}_{3}{ }^{+}$to abrade the films layer by layer, on concentric but larger areas of $700 \mathrm{x} 700 \mu \mathrm{m}^{2}$. For both reference films (A and $\mathrm{C}$ ) and for the $\mathrm{AC}$ gradient film three depth profiling have been performed at randomly selected areas to verify and confirm the measurement reproducibility and the film homogeneity.

\section{Determination of surface wettability}

Finally, the wettability of the $\mathrm{NH}_{2}-\mathrm{PPF}$ with and without vertical chemical gradients was compared using dynamic water contact angle (WCA) measurements. A water drop (CHROMASOLV®, for HPLC, Sigma Aldrich) of $5 \mu \mathrm{L}$ was firstly deposited, and then, the drop increased $(30 \mu \mathrm{L} / \mathrm{min})$ until it reached a volume of $50 \mu \mathrm{L}$, and finally decreased (30 $\mu \mathrm{L} / \mathrm{min})$ until $3 \mu \mathrm{L}$. All WCAs were measured and registered automatically by the software (Krüss, DSA25), taking 5 measurements per second. Before starting the experiment, the needle was well positioned to ensure reliable data. ${ }^{37}$ 


\section{Behavior of the gradient coating during air and water aging}

\section{Evolution of the surface wettability}

To investigate the stability of the plasma polymer film, static WCA (Krüss, DSA25) were measured depositing at least 3 drops $(2 \mu \mathrm{L})$ of water (CHROMASOLV ${ }^{\circ}$, for HPLC, Sigma Aldrich) on fresh and aged samples stored in air.

Evolution of the surface chemistry

Evolution of the chemical composition of the samples during air and water aging was measured using a Scanning XPS Microprobe (XPS PHI VersaProbe II spectrometer, Physical Electronics) with monochromatic $\mathrm{Al}-\mathrm{K}_{\alpha}$ radiation $(1486.6 \mathrm{eV})$ and a take-off angle of $45^{\circ}$. The operating pressure of the XPS analysis chamber was below $5 \times 10^{-7} \mathrm{~Pa}$ during the measurements. For each sample, a randomly chosen spot was analyzed using a micro-focused X-ray beam with a diameter of $100 \mu \mathrm{m}$. Survey scan spectra (0-1100 eV) were acquired with an energy step width of $0.8 \mathrm{eV}$, with an acquisition time of $160 \mathrm{~ms}$ per data point and with analyzer pass energies of $187.85 \mathrm{eV}$. Obtained spectra were rescaled by shifting the spectra relative to the aliphatic carbon at $285 \mathrm{eV}$. Data treatment and peak-fitting procedures were performed using CasaXPS software version 2.3.16. For quantification, PHI sensitivity factors ${ }^{38}$ were corrected for our system's transmission function and spectrometer geometry (asymmetry function).

\section{Results and Discussion}

\section{Characterization of single layer films}

Before preparing a vertical chemical gradient of amine-containing PPFs, it is necessary to carefully define the plasma conditions that will be used to prepare the cross-linked first (base) 
layer. This base layer indeed plays a crucial role in the stability of the whole coating prepared with a vertical chemical gradient.

To find suitable conditions to deposit the cross-linked base layer, the film density of the PPFs was investigated. This density is an indication of the PPF's cross-linking degree, which, in turn, is inversely related to the number of functional groups. ${ }^{23,29}$ Also, a macroscopic approach was used to determine the chemical reaction pathway. Therefore, the mass deposition rate can be plotted as a function of the inverse energy input, as shown in Figure 1. The deposited mass follows an Arrhenius-like behavior over a broad parameter range, which is indicated by straight lines. Within this regime, a predominant reaction pathway to produce film-forming species exists resulting in an invariable elemental film composition (i.e. $[\mathrm{N}] /[\mathrm{C}]$ ratio). Based on these investigations, the plasma parameters to deposit the base layer coating were chosen: gas flow rate of $7 \mathrm{sccm} \mathrm{C}_{2} \mathrm{H}_{4}$ and $4 \mathrm{sccm} \mathrm{NH}_{3}$, i.e. excess of hydrocarbon to support cross-linking, constant pressure of $10 \mathrm{~Pa}$, and high power input of $70 \mathrm{~W}$. In the following, this coating is referred as "A-coating" (see Table 1 and Figure 1). PPFs deposited under these conditions had a rather high film density (about 1.4-1.5 $\mathrm{g} \mathrm{cm}-3$ ), but were still within the Arrhenius-regime. Therefore, it can be assumed that these coatings were highly cross-linked, hence, less functional, but stable. 
Table 1. Overview of the used process parameters to deposit the different gradient layers. Frequency and pressure were kept constant at $13.56 \mathrm{MHz}$ and $10 \mathrm{~Pa}$, respectively. B layer is given here as it corresponds to the unwanted but formed intermediate layer while preparing the vertical gradient.

\begin{tabular}{ccccc}
\hline Layer & $\mathrm{C}_{2} \mathrm{H}_{4} / \mathrm{sccm}$ & $\mathrm{NH}_{3} / \mathrm{sccm}$ & Power Input / W & Characteristics \\
\hline $\mathrm{A}$ & 7 & 4 & 70 & more cross-linked \\
$\mathrm{B}$ & 7 & 4 & 50 & \\
$\mathrm{C}$ & 7 & 7 & 50 & more functional \\
\hline
\end{tabular}

\section{Preparation of the vertical chemical gradient}

An already developed procedure ${ }^{26}$ was used to prepare the $\mathrm{NH}_{2}-\mathrm{PPF}$ with vertical chemical gradient (this coating is referred as "AC-coating"): i) $15 \mathrm{~nm}$ of the base layer (A-layer) was firstly deposited onto the substrate, then ii) the power input decreased from $70 \mathrm{~W}$ to $50 \mathrm{~W}$ (within 2-3 seconds, direct control of the plasma conditions, providing plasma conditions for deposition of B-layer), then iii) the gas flow ratio was adjusted from 7:4 to 7:7, and, finally, iv) $2 \mathrm{~nm}$ of functional top-layer (C-layer) was deposited, keeping the plasma "switched on" all over the procedure. The previously optimized C-layer has a slightly lower film density of about 1.3-1.4 $\mathrm{g} \mathrm{cm}^{-3}$. Well-defined plasma chemistry is expected when the base layer and the top-layer are deposited, due to the steady deposition conditions. Deposition conditions, however, change when the power input is decreased and when the gas flow ratio is altered. On one hand, decreasing the power input might not change the plasma chemistry as this step clearly follows the Arrhenius-like regime, as depicted in Figure 1, but slightly decreases the degree of crosslinking in the film, due to less ion bombardment (the plasma coating that is deposited, i.e. B 
layer, is thus expected to be slightly less cross-linked that A layer forming part of the transition layer of the gradient). On the other hand, plasma chemistry is assumed to be changed when the gas flow ratio is adjusted (the two different Arrhenius curves related to the chemical reaction pathways are given in Figure 1, where data given for the 1:1 were taken from a previous study ${ }^{39}$ ).

The chemical species present in the plasma zone were analyzed by OES. A typical spectrum in the wavelength range from $300 \mathrm{~nm}$ to $460 \mathrm{~nm}$, taken in a discharge for C-coating, is shown in Figure 2a. Several transition peaks occur due to the decomposition and recombination reactions of ammonia. The most pronounced emission lines can be seen for the CN species $(388.3 \mathrm{~nm})$, NH species $(336.0 \mathrm{~nm}), \mathrm{N}_{2}$ species $(337.1 \mathrm{~nm}, 357.7 \mathrm{~nm})$ and $\mathrm{CH}$ species $(431.4 \mathrm{~nm}) .{ }^{31,35,40}$ It is important to note here that the observed $\mathrm{NH}, \mathrm{N}_{2}$ and $\mathrm{CH}$ species are related to reactions occurring in the plasma zone, i.e. plasma chemistry, whereas $\mathrm{CN}$ species are related to the plasma/surface interaction, that is to say these species are created at the surface of the coating and then etched during the process making them visible by OES measurement. ${ }^{41}$

In Figure $2 \mathrm{~b}$ and Figure $2 \mathrm{c}$, the time evolution of the intensities of the most pronounced transition peaks are shown. The sum of the intensities of the used species was normalized to one. In Figure $2 \mathrm{~b}$, the process parameters of the plasma were changed from A- to B-conditions after roughly $10 \mathrm{~s}$. The chemistry in the plasma zone remained constant over time, as the relative intensity measured for $\mathrm{N}_{2}, \mathrm{NH}$ and $\mathrm{CH}$ species were similar over time, which is in accordance with the Arrhenius regime. A slight decrease regarding the intensity measured for $\mathrm{CN}$ species is observed and can be explained by the condition change: from A-conditions to B-conditions, the power input was decreased from $70 \mathrm{~W}$ to $50 \mathrm{~W}$, and thus, a lower energy was deposited by reduced ion bombardment into the growing film leading to reduced etching. In Figure $2 \mathrm{c}$, the parameters were changed from A- to C-conditions. This change implies a different gas 
composition (not following the Arrhenius-like regime) and, therefore, a change in chemistry can be expected. The effect can clearly be seen after $10 \mathrm{~s}$ as the intensity of $\mathrm{NH}$ increases. Moreover, the evolution of the intensity related to $\mathrm{CN}$ species can be explained by the change in plasma conditions as well: firstly, the power input was decreased from $70 \mathrm{~W}$ to $50 \mathrm{~W}$, thus decreasing the number of $\mathrm{CN}$ species in the plasma zone, and then, gas flow ratio $\left(\mathrm{NH}_{3} / \mathrm{C}_{2} \mathrm{H}_{4}\right)$ was increased from 4:7 to $7: 7$, increasing the number of nitrogen-containing species available and thus also the number of $\mathrm{CN}$ species in the plasma zone (by etching).

Overall, these observations were helpful to verify the previous assumption: 1) the chemistry in the plasma zone remained the same when the power input was altered from $70 \mathrm{~W}$ to $50 \mathrm{~W}$, and 2) the plasma chemistry changed when the gas flow ratio $\left(\mathrm{NH}_{3} / \mathrm{C}_{2} \mathrm{H}_{4}\right)$ was adjusted from 4:7 to 7:7.

\section{Characterization of the vertical chemical gradient}

As observed, some changes occurred in the plasma zone while preparing the vertical chemical gradient. Thus, modifications of the plasma polymer films can be expected. QCM was used to follow the thickness of the film (Figure 3) while depositing the gradients. As the film density of A and $\mathrm{C}$ layers were similar, the input density was set at $1.4 \mathrm{~g} \mathrm{~cm}^{-3}$ and the obtained data can be read directly without any further calculation.

After roughly one minute, the shutter which prevents the quartz crystal to be coated was opened, and the deposition on the Ag-coated quartz crystal started. Initially, the deposition rate firstly increased before it reached steady-state conditions of $11.5 \mathrm{~nm} \mathrm{~min}^{-1}$. This phenomenon is related 
to the initial growth of plasma polymer films on the Ag-coated crystal, ${ }^{25,42,43}$ since the filmforming species have a lower sticking probability on Ag.

After about two minutes, plasma conditions were changed from the process parameters for A- to C-coating. Change of power input can be immediately observed by an immediate step in the thickness of the coating. Changing the gas flow ratio, on the other hand, took $\sim 10 \mathrm{~s}$ after setting the new conditions. After reaching deposition conditions related to the C-coating, a steady-state and lower deposition rate of $8.3 \mathrm{~nm} \mathrm{~min}^{-1}$ was obtained. Note that the deposition rates measured by QCM are lower than the ones obtained directly at the electrode because of the recessed position of the quartz crystal in the holder.

As QCM cannot give information on the chemistry of the film, depth profiling-XPS was carried out (Figures 4 and S1) onto thicker layers, i.e. references A, C with a thickness of $\sim 50 \mathrm{~nm}$ and gradient $\mathrm{AC}$ with a thickness of $\sim 60 \mathrm{~nm}$ but with a comparable gradient structure as thinner coatings. This way, a sufficient thickness of the top-layer can be analyzed before starting to observe the gradient, ensuring a complete analysis of the full gradient structure.

Initially, single layers of A- and C-coatings were sputtered with argon clusters and analyzed by XPS. The etch rates of $10 \mathrm{keV} \mathrm{Ar}_{1000}{ }^{+}$were determined as $0.7 \mathrm{~nm} \min ^{-1}$ and $1.4 \mathrm{~nm} \mathrm{~min}^{-1}$ for coating $\mathrm{A}$ and $\mathrm{C}$, respectively. The clearly different etch rate values also indicated that the $\mathrm{A}$ layer was more cross-linked than the $\mathrm{C}$ layer. Moreover, the same chemical composition was observed all over the depth of these two coatings $(\mathrm{C} 1 \mathrm{~s}=84$ at.\%, N1s $=13$ at.\% and $\mathrm{O} 1 \mathrm{~s}=3$ at. $\%$ for coating $\mathrm{A} ; \mathrm{C} 1 \mathrm{~s}=79$ at. $\%, \mathrm{~N} 1 \mathrm{~s}=17$ at. $\%$ and $\mathrm{O} 1 \mathrm{~s}=4$ at. $\%$ for coating $\mathrm{C}$ ), showing the homogeneity of the film (Figure S1), except for the first few nanometers on top that are oxidized. A depth profile analysis of the gradient coating was also carried out (Figure 4). The top surface 
was also oxidized as for coating $\mathrm{A}$ and $\mathrm{C}$, and the two layers were well-defined and wellseparated. This result shows that both layers were very homogeneous and well spatially-defined over the thickness of the film. However, the transition in between these two layers was difficult to observe.

Thus, further studies were carried out using ToF-SIMS in order to better resolve the transition (B) layer and to analyze its chemistry in more detail. To ensure relevant results and to avoid any potential chemical changes related to the film thickness, thinner coatings were analyzed by ToFSIMS: reference (A and C) and gradient (AC) coatings were $35 \mathrm{~nm}$ thick, and the $\mathrm{AC}$ coating was prepared by depositing $\sim 20 \mathrm{~nm}$ of the $\mathrm{C}$ coating onto $\sim 15 \mathrm{~nm}$ of A coating, while keeping the same gradient structure. Figure 5 shows the in-depth evolution of two selected nitrogencontaining fragments, i.e. $\mathrm{C}_{2} \mathrm{~N}_{3}^{-}$(Figure 5a) and $\mathrm{C}_{4} \mathrm{~N}_{3} \mathrm{H}_{2}{ }^{-}$(Figure 5b), for the $\mathrm{A}, \mathrm{C}$ and $\mathrm{AC}$ coatings. As expected, more nitrogen-containing fragments were observed in the $\mathrm{C}$ layer than in the A layer. Regarding the gradient coating AC, the top-layer showed respective intensities of $\mathrm{C}_{2} \mathrm{~N}_{3}{ }^{-}$and $\mathrm{C}_{4} \mathrm{~N}_{3} \mathrm{H}_{2}^{-}$fragments similar to those of the $\mathrm{C}$ coating and the base layer showed intensities of $\mathrm{C}_{2} \mathrm{~N}_{3}{ }^{-}$and $\mathrm{C}_{4} \mathrm{~N}_{3} \mathrm{H}_{2}{ }^{-}$fragments similar to those of the A coating, as expected. At the interface in between both layers, a regular decrease of the $\mathrm{C}_{2} \mathrm{~N}_{3}{ }^{-}$and $\mathrm{C}_{4} \mathrm{~N}_{3} \mathrm{H}_{2}{ }^{-}$fragment intensities spanning over $\sim 5 \mathrm{~nm}$ was observed, highlighting a homogeneous gradient structure in the transition layer.

After characterization of the gradient structure, the wettability of the AC-coating $(\sim 20 \mathrm{~nm}$ thick coating) was compared to the wettability of various $\mathrm{NH}_{2}$-PPFs (20 nm thick coatings): $\mathrm{A}$, B and $\mathrm{C}$ layers, and also intermediate conditions in between $\mathrm{B}$ and $\mathrm{C}$ layers considering gas flow ratios of 7:5 and 7:6 $\left(\mathrm{C}_{2} \mathrm{H}_{4} / \mathrm{NH}_{3}\right)$. The measured advancing and receding angles are given in Figure 6. 
A first observation concerns the transition in between the A and B layer: the advancing contact angle was comparable, but the receding contact angle was slightly lower in the case of B layer. This could be explained by the lower power input applied to prepare the B coating, resulting in reduced cross-linking and enhanced interaction with water molecules. Then, wettability of the surface increased with the increase of the $\mathrm{NH}_{3}$ gas flow rate in the plasma chamber. Indeed, as there was more ammonia in the plasma zone, more film-forming species included nitrogencontaining chemical groups, leading to the formation of amine, imine, and amide groups, for example. Thus, the surface was more functionalized, showing a lower advancing angle, and was more susceptible to surface hydration, explaining the lower receding angle. In the case of the gradient coating, an advancing angle of $59 \pm 1^{\circ}$ and a receding angle of $37 \pm 1^{\circ}$ were measured -

in good agreement with the values measured in the case of the $\mathrm{C}$ layer (advancing angle of $60 \pm 1^{\circ}$ and receding angle of $36 \pm 1^{\circ}$ ). Thus, the surface wettability of the AC coating was equivalent to the surface wettability of the $\mathrm{C}$ layer, as expected.

\section{Behavior of the gradient coating during air aging}

The stability of the AC gradient coating ( $\sim 20 \mathrm{~nm}$ thick coating) in air was investigated, taking the $\mathrm{C}$-coating as a reference. Both coatings, i.e. $\mathrm{C}$ and $\mathrm{AC}$, showed the same behavior when aged in air. Indeed, the measured WCA on the two freshly prepared coatings was about $55 \pm 3^{\circ}$ and reached $60 \pm 1^{\circ}$ during the first few hours after plasma deposition. This increase was due to the passivation (or "inactivation") of radical species still present in the PPF after plasma deposition. A similar WCA $\left(60^{\circ}\right)$ was also measured after 1,2 and 3 months, showing that the wettability of the surface was stable over time in air. 
Aged samples were also analyzed by XPS to evaluate their chemical composition over time. C layer and AC-coating aged in a similar way in air, as the same $[\mathrm{N}] /[\mathrm{C}]$ ratio can be observed over time (Figure $7 \mathrm{a}$ ): $[\mathrm{N}] /[\mathrm{C}] \sim 17.4 \%$ for $\mathrm{C}$ coating and $\sim 16.6 \%$ for AC coating over 1 week in air. The slightly lower $[\mathrm{N}] /[\mathrm{C}]$ ratio for the AC coating can be explained by the fact that $\sim 6 \mathrm{~nm}$ of the top surface was analyzed by XPS (information depth), and thus, not only the top-layer C, but also a part of the base layer A, which contains less nitrogen, gave a signal while analyzing the AC gradient. Oxidation processes at the surface of both samples were also similar: $[\mathrm{O}] /[\mathrm{C}]$ ratios were at $10.6 \%$ and $10.8 \%$ for fresh C-and AC-coatings, respectively, and then increased to $15.6 \%$ and $13.3 \%$ after one day in air, to finally reach $16.0 \%$ and $15.6 \%$ after one week in air. Thus, a slight delay of the oxidation process is assumed for the gradient AC-coating as compared to the C-coating during the first few days, however, the AC-coating was clearly oxidized in a comparable manner as the $\mathrm{C}$ layer after one week. Such oxidation processes are also accompanied by a slight decrease of the $\left[\mathrm{NH}_{2}\right] /[\mathrm{C}]$ amount. ${ }^{6,8,18}$

\section{Behavior of the gradient coating during water aging}

Since amino-containing PPFs are discussed as biointerfaces, the stability of the investigated coatings, namely the gradient $\mathrm{AC}$ and the $\mathrm{C}$ coating, were also investigated by storage in distilled water. The results indicate the stabilization effect of the top-layer thanks to the base layer within the gradient structure: while the $\mathrm{C}$ coating showed stability in water for about one day followed by severe film loss for prolonged storage in aqueous conditions (indicated by the loss of nitrogen functionalities from $[\mathrm{N}] /[\mathrm{C}] \sim 14.5 \%$ at the first day to $[\mathrm{N}] /[\mathrm{C}] \sim 6.0 \%$ after 1 week in distilled water), the vertical gradient structure revealed a constant chemical composition 
$([\mathrm{N}] /[\mathrm{C}] \sim 14.7 \%)$ even after one week in water. Moreover, the thickness of the gradient containing $\mathrm{NH}_{2}$-PPF (AC layer) remained stable over time: $21 \pm 3 \mathrm{~nm}$ after $1 \mathrm{~h}$ in air, $23 \pm 2 \mathrm{~nm}$ after $5 \mathrm{~min}$ in water, $21 \pm 3 \mathrm{~nm}$ after 1 day in water, and still $21 \pm 2 \mathrm{~nm}$ after 1 week in water. On the contrary, a slight decrease of the $\mathrm{NH}_{2}$-PPF single layer (C layer) was observed: initially, the film had a thickness of $22 \pm 2 \mathrm{~nm}$, and then, thickness decreased giving $22 \pm 2 \mathrm{~nm}, 21 \pm 3 \mathrm{~nm}$ and $17 \pm 2 \mathrm{~nm}$ after immersion in water for $5 \mathrm{~min}, 1$ day and 1 week, respectively. Additional XPS measurements, with chemical derivatization using TFBA, were carried out to determine the $\left[\mathrm{NH}_{2}\right] /[\mathrm{C}]$ ratio before and after 1 week of water storage. An initial $\left[\mathrm{NH}_{2}\right] /[\mathrm{C}]$ ratio of $1.2 \pm 0.3 \%$ was measured for both coatings (with or without gradient), whereas after 1 week in water, a clear difference in chemical composition was observed: the $\left[\mathrm{NH}_{2}\right] /[\mathrm{C}]$ ratio remained constant for the gradient-containing $\mathrm{NH}_{2}$-PPF, whereas a strong decrease of the $\left[\mathrm{NH}_{2}\right] /[\mathrm{C}]$ ratio was observed for the $\mathrm{NH}_{2}$-PPF single layer (no amino groups were detectable anymore). These observations thus give a first hint showing less dissolution for the gradient-containing $\mathrm{NH}_{2}$-PPF. Indeed, water penetration should be reduced in the gradient coating due to its more cross-linked base-layer structure. Anyway, the chemical composition of the top-layer is similar to the chemical composition of the $\mathrm{NH}_{2}-\mathrm{PPF}$ single layer. Thus, partial dissolution of the top-layer - similar as observed for oxygen functional $\mathrm{PPFs}^{28}$ - can be expected. Further investigations on this stabilization effect are ongoing. 


\section{Conclusion}

An amino-containing plasma polymer film (PPF) comprising a vertical chemical gradient was prepared by plasma deposition under low pressure conditions. By combining plasma diagnostics (OES and QCM) during deposition and depth profiling (with XPS and ToFSIMS) of the deposited coating, interdependence between chemical composition of the coating layer and $\mathrm{NH}_{3} / \mathrm{C}_{2} \mathrm{H}_{4}$ gas flow ratio was proven, indicating the importance of gas phase processes during plasma polymerization. Surface processes (ion bombardment), on the other hand, are largely responsible to enhance the cross-linking of the PPF, however, on the expense of functionality. On this basis, a more cross-linked base layer (coating A) and a rather stable, yet more functional top-layer (coating C) have been selected to deposit the vertical chemical gradient film. Thus, a transition layer was observed in between the well-defined A and $\mathrm{C}$ layers. This transition layer consists in a gradual change in the nitrogen-containing fragments with a lower content near the A layer (concentration equivalent to A coating), and a higher content near the $\mathrm{C}$ layer (concentration equivalent to $\mathrm{C}$ coating). Surface properties of the gradient $\mathrm{NH}_{2}$-containing PPF were observed to be similar to the surface properties of the single layer as wettability was observed to be similar. Aging study in air of both coatings gave similar results: a similar WCA value of $\sim 60^{\circ}$ was measured, and the chemical composition was similar, as well, showing a constant $[\mathrm{N}] /[\mathrm{C}]$ ratio and a slight oxidation while aging for one week in air. Hence, a comparable air stability of the $\mathrm{NH}_{2}$-PPFs with and without gradient could be obtained thanks to the used optimized plasma deposition conditions.

For prolonged storage in water (exceeding one day), on the other hand, the gradient structure was found to be significantly more stable, i.e. not showing film loss and changes in the elemental composition upon immersion time (measured up to one week). Moreover, 
the functionality $\left(\left[\mathrm{NH}_{2}\right] /[\mathbf{C}]\right.$ of $\left.\sim \mathbf{1 \%}\right)$ was maintained. This is an important finding as $\mathrm{NH}_{2}$ PPFs are known for their low stability in water. The potential of optimized functional PPFs comprising vertical chemical gradients were demonstrated, for example for bio-sensing applications where stability in aqueous media is essential.

\title{
Supplementary Information
}

Supporting information available: XPS depth profile of the A- and of the C-coating. This material is available and free of charge on the ACS Publications website (http://pubs.acs.org).

\author{
Author information \\ *Corresponding author: Marianne Vandenbossche \\ marianne.vandenbossche@empa.ch, tel. +41587657112
}

\section{Note}

The authors declare no competing financial interest.

\section{Acknowledgements}

The authors gratefully acknowledge the Swiss National Science Foundation (SNSF, Bern) for funding this study under grant no. IZ73Z0_152661 (SCOPES) and the European Union Seventh Framework Program (FP7/2007-2013) for funding this study under grant agreement no. 316216. 


\section{References}

(1) Makhneva, E.; Manakhov, A.; Skladal, P.; Zajickova, L. Development of effective QCM biosensors by cyclopropylamine plasma polymerization and antibody immobilization using cross-linking reactions. Surf. Coat. Technol. 2016, 290, 116-123.

(2) Wang, H.; Wang, C.; Lei, C.; Wu, Z.; Shen, G.; Yu, R. A novel biosensing interfacial design produced by assembling nano-Au particles on amine-terminated plasma-polymerized films. Anal. Bioanal. Chem. 2003, 377, 632-638.

(3) Robinson, D.E.; Al-Bataineh, S.A.; Farrugia, B.L.; Michelmore, A.; Cowin, A.J.; Dargaville, T.R.; Short, R.D.; Smith, L.E.; Whittle, J.D. Plasma Polymer and Biomolecule Modification of 3D Scaffolds for Tissue Engineering. Plasma Process. Polym. 2016, 13, 678689.

(4) Mwale, F.; Rampersad, S.; Ruiz, J.-C.; Girard-Lauriault, P.-L.; Petit, A.; Antoniou, J.; Lerouge, S.; Wertheimer, M.R. Amine-Rich Cell-Culture Surfaces for Research in Orthopedic Medicine. Plasma Med. 2011, 1(2), 115-133.

(5) Siow, K.S.; Brichter, L.; Kumar, S.; Griesser, H.J. Plasma Methods for the Generation of Chemically Reactive Surfaces for Biomolecule Immobilizatioon and Cell Colonization - A Review. Plasma Process. Polym. 2006, 3, 392-418.

(6) Gengenbach, T.R.; Chatelier, R.C.; Griesser, H.J. Characterization of the Ageing of Plasma-deposited Polymer Films: Global Analysis of X-ray Photoelectron Spectroscopy Data. Surf. Interface Anal. 1996, 24, 271-281.

(7) Girard-Lauriault, P.-L.; Dietrich, P.M.; Gross, T.; Wirth, T.; Unger, W.E.S. Chemical characterization of the long-term ageing of nitrogen-rich plasma polymer films under various ambient conditions. Plasma Process. Polym. 2013, 10(4), 388-395.

(8) Hegemann, D.; Hanselmann, B.; Guimond, S.; Fortunato, G.; Giraud, M.-N.; Guex, A.G. Considering the degradation effects of amino-functional plasma polymer coatings for biomedical application. Surf. Coat. Technol. 2014, 255, 90-95.

(9) Manakhov, A.; Zajickova, L.; Elias, M.; Cechal, J.; Polcak, J.; Hnilica, J.; Bittnerova, S.; Necas, D. Optimization of Cyclopropylamine Plasma Polymerized toward Enhanced Layer Stability in Contact with Water. Plasma Process. Polym. 2014, 11(6), 532-544.

(10) Li, L.; Dai, X.J.; Xu, H.S.; Zhao, J.H.; Yang, P.; Maurdev, G.; du Plessis, J.; Lamb, P.R.; Fox, B.L.; Michalski, W.P. Combined Continuous Wave and Pulsed Plasma Modes: For More Stable Interfaces with Higher Functionality on Metal and Semiconductor Surfaces, Plasma Process. Polym. 2009, 6, 615-619.

(11) Chatelier, R.C.; Xie, X.; Gengenbach, T.R.; Griesser, H.J. Quantitative Analysis of Polymer Surface Restructuring. Langmuir 1995, 11, 2576-2584.

(12) Hegemann, D. Plasma Polymer Deposition and Coatings on Polymer. In Comprehensive Materials Processing; S. Hashmi, Ed.; Elsevier Ltd. 2014, Chapter 9, Vol. 4, 201-228.

(13) Jokinen, V.; Suvanto, P.; Franssila, S. Oxygen and nitrogen plasma hydrophilization and hydrophobic recovery of polymers. Biomicrofluidics 2012, 6, 016501.

(14) Bacharouche, J.; Haidara, H.; Kunemann, P.; Vallat, M.-F.; Roucoules, V. Singularities in hydrophobic recovery of plasma treated polydimethylsiloxane surfaces under non-contaminant atmosphere. Sensor Actuat. A-Phys 2013, 197, 25-29.

(15) Behnisch, J.; Holländer, A.; Zimmermann, H. Factors influencing the hydrophobic recovery of oxygen-plasma-treated polyethylene. Surf. Coat. Technol. 1993, 59, 356-358. 
(16) Holländer, A.; Thome, J. Degradation and Stability of Plasma Polymers. In Plasma Polymer Films; H. Biedermann, Ed.; Imperial College Press, 2004, Chapter 7, 246-278.

(17) Hegemann, D. Controlling the nanostructure and stability of a-C:H:N plasma polymers. Thin Solid Films 2015, 581, 2-6.

(18) Ruiz, J.C.; St-Georges-Robillard, A.; Thérésy, C.; Lerouge, S.; Wertheimer, M.R. Fabrication and charaterisation of amine-rich organic thin films: Focus on stability. Plasma Process. Polym. 2010, 7(9-10), 737-753.

(19) Zhang, Z.; Chen, Q.; Knoll, W.; Foerch, R. Effect of aqueous solution on functional plasma polymerized films. Surf. Coat. Technol. 2003, 174-175, 588-590.

(20) Vasilev, K.; Brichter, L.; Casanal, A.; Griesser, H.J. Solvent-induced Porosity in Ultrathin Amine Plasma Polymer Coatings. J. Phys. Chem. B 2008, 112(35), 10915-10921.

(21) Finke, B.; Schröder, K.; Ohl, A. Structure retention and water stability of microwave plasma polymerized films from allylamine and acrylic acid. Plasma Process. Polym. 2009, 6, S70-S74.

(22) Detomaso, L.; Gristina, R.; Senesi, G.S.; d'Agostino, R.; Favia, P. Stable plasmadeposited acrylic acid surfaces for cell culture applications. Biomaterials 2005, 26(18), 38313841 .

(23) Hegemann, D.; Körner, E.; Blanchard, N.E.; Drabik, M.; Guimond, S. Densification of functional plasma polymers by momentum transfer during film growth. Appl. Phys. Lett. 2012, $101,211603$.

(24) Hegemann, D.; Hanselmann, B.; Blanchard, N.; Amberg, M. Plasma-Substrate Interaction during Plasma Deposition on Polymers. Contrib. Plasma Phys. 2014, 54(2), 162-169.

(25) Vandenbossche, M.; Butron Garcia, M.-I.; Schütz, U.; Rupper, P.; Amberg, M.; Hegemann, D. Initial Growth of Functional Plasma Polymer Nanofilms. Plasma Chem. Plasma Process. 2016, 36, 667-677.

(26) Hegemann, D.; Lorusso, E.; Butron Garcia, M.-I.; Blanchard, N.E.; Rupper, P.; Favia, P.; Heuberger, M.; Vandenbossche, M. Suppression of Hydrophobic recovery by Plasma Polymer Films with Vertical Chemical Gradients. Langmuir 2016, 32, 651-654.

(27) Hegemann, D.; Blanchard, N.E.; Heuberger, M. Reduced Protein Adsorption on Plasma Polymer Films Comprising Hydrophobic/Hydrophilic Vertical Chemical Gradients. Plasma Process. Polym. 2016, 13, 494-498.

(28) Rupper, P.; Vandenbossche, M.; Bernard, L.; Hegemann, D.; Heuberger, M. Composition and Stability of Plasma Polymer Films Exhibiting Vertical Chemical Gradients. Langmuir 2017, $33,2340-2352$.

(29) Hegemann, D.; Michlicek, M.; Blanchard, N.E.; Schütz, U.; Lohmann, D.; Vandenbossche, M.; Zajickova, L.; Drabik, M. Deposition of Functional Plasma Polymers Influenced by Reactor Geometry in Capacitively Coupled Discharges. Plasma Process. Polym. 2016, 13(2), 279-286.

(30) Thiry, D.; Konstantinidis, S.; Cornil, J.; Snyders, R. Plasma diagnostics for the lowpressure plasma polymerization process: A critical review. Thin Solid Films 2016, 606, 19-44.

(31) Arefi-Khonsari, F.; Kurdi, J.; Tatoulian, M.; Amouroux, J. On plasma processing of polymers and the stability of the surface properties for enhanced adhesion to metals. Surf. Coat. Technol. 2001, 142-144, 437-448.

(32) Hegemann, D.; Schütz, U.; Körner, E. Macroscopic approach to plasma polymerization using the concept of energy density. Plasma Process. Polym. 2011, 8(8), 689-694. 
(33) Park, S.Y.; Kim, N.; Kin, U.Y.; Hong, S.I.; Sasabe, H. Plasma polymerization of hexamethyldisilazane. Polym. J. 1990, 22(3), 242-249.

(34) Gleason, K.K. A chemical engineering perspective on ,Views on macroscopic kinetics of plasma polymerisation“. Plasma Process. Polym. 2010, 7(5), 380-381.

(35) Buddhadasa, M.; Girard-Lauriault, P.-L. Plasma co-polymerisation of ethylene, 1,3butadiene and ammonia mixtures: Amine content and water stability. Thin Solid Films 2015, 591, 76-85.

(36) Kurosawa, S.; Aizawa, H.; Miyake, J.; Yoshimoto, M.; Hilborn, J.; Talib, Z.A. Detection of deposition rate of plasma-polymerized silicon-containing films by quartz crystal microbalance. Thin Solid Films 2002, 407, 1-6.

(37) Korhonen, J.T.; Huhtamäki, T.; Ikkala, O.; Ras, R.H.A. Reliable Measurement of the Receding Contact Angle. Langmuir 2013, 29, 3858-3863.

(38) Moulder, J.F.; Stickle, W.F.; Sobol, P.E.; Bomben, K.D. Handbook of X-ray Photoelectron Spectroscopy; J. Chastain, Ed.; Perkin-Elmer Corp: Eden Prairie, 1992.

(39) Guimond, S.; Schütz, U.; Hanselmann, B.; Körner, E.; Hegemann, D. Influence of gas phase and surface reactions on plasma polymerization. Surf. Coat. Technol. 2011, 205, S447S450.

(40) Clay, K.J.; Speakman, S.P.; Amaratunga, G.A.J.; Silva, S.R.P. Characterization of C:H:N deposition from $\mathrm{CH} 4 / \mathrm{N}-2$ rf plasmas using optical emission spectroscopy. J. Appl. Phys. 1996, $79,7227-7233$.

(41) Vandenabeele, C.; Buddhadasa, M.; Girard-Lauriault, P.-L.; Snyders, R. Comparison between single monomer versus gas mixture for the deposition of primary amine-rich plasma polymers. Thin Solid Films 2017, 630, 100-107.

(42) Hwang, S.; Seo, H.; Jeong, D.-C.; Wen, L.; Han, J.G.; Song, C.; Kim Y. Growth kinetics of plasma-polymerized films. Sci. Rep. 2015, 5,11201.

(43) Michelmore, A.; Martinek, P.; Sah, V.; Short, R.; Vasilev, K. Surface Morphology in the Early Stages of Plasma Polymer Film Growth from Amine-Containing Monomers. Plasma Process. Polym. 2011, 8, 367-372. 


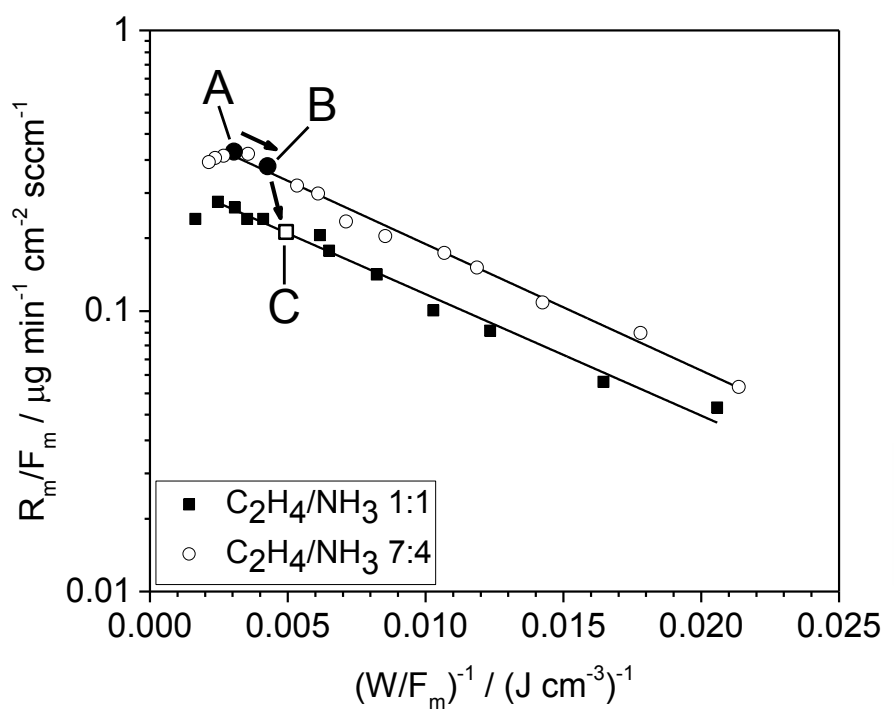

\section{C layer}

\section{$\Uparrow$ transition}

\section{A layer}

Figure 1. Arrhenius-like plot of the mass deposition rate per monomer gas flow $\left(\mathrm{R}_{\mathrm{m}} / \mathrm{F}_{\mathrm{m}}\right)$ as a function of the inverse energy input per monomer gas flow $\left(\left(\mathrm{W} / \mathrm{F}_{\mathrm{m}}\right)^{-1}\right)$ for $\mathrm{C}_{2} \mathrm{H}_{4} / \mathrm{NH}_{3}$ plasmas. The Arrhenius regimes are indicated by straight lines. Data given for the 1:1 were taken from a previous study. ${ }^{32}$ The vertical chemical gradient is made by depositing first the base layer A, and then, by decreasing the power to reach transitional B-conditions, and finally, by changing the gas flow ratio reaching plasma conditions of the top-layer $\mathrm{C}$. The resulting gradient coating is shown next to the Arrhenius-like plot. 
a)

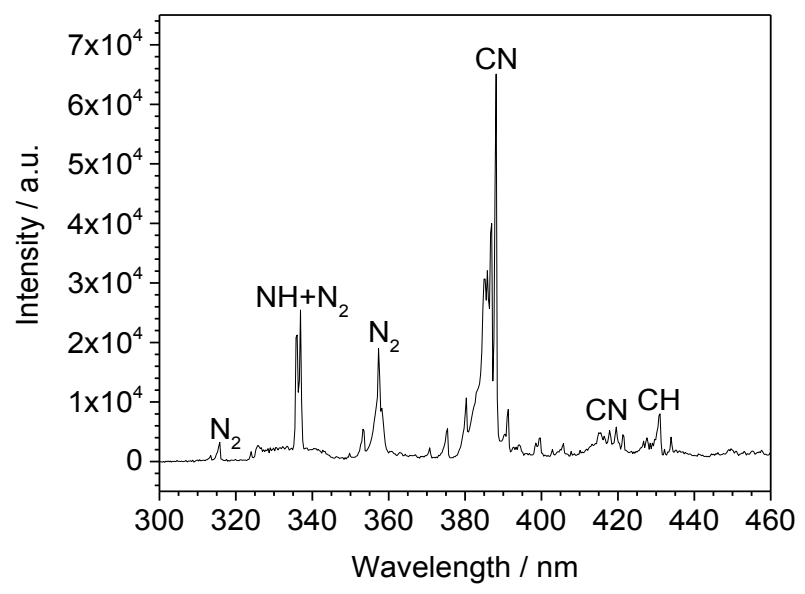

b)

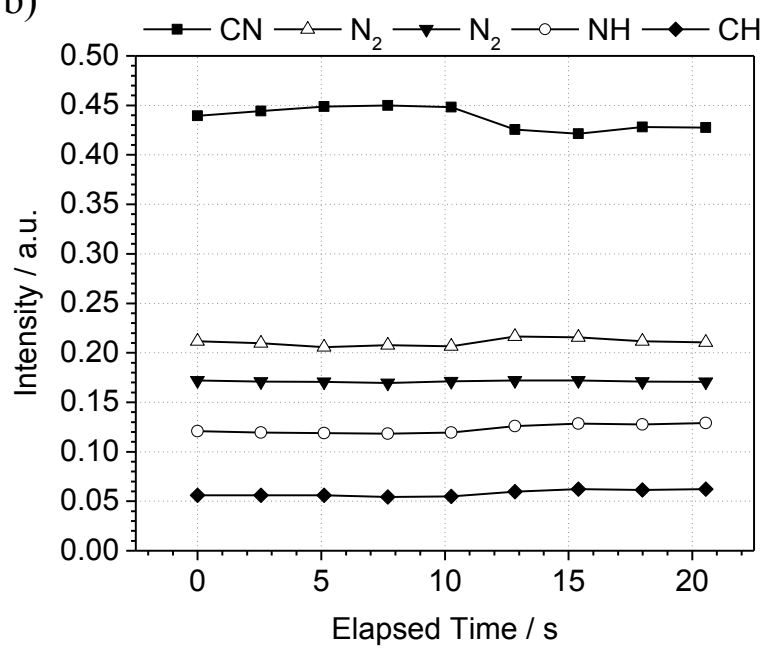

c)

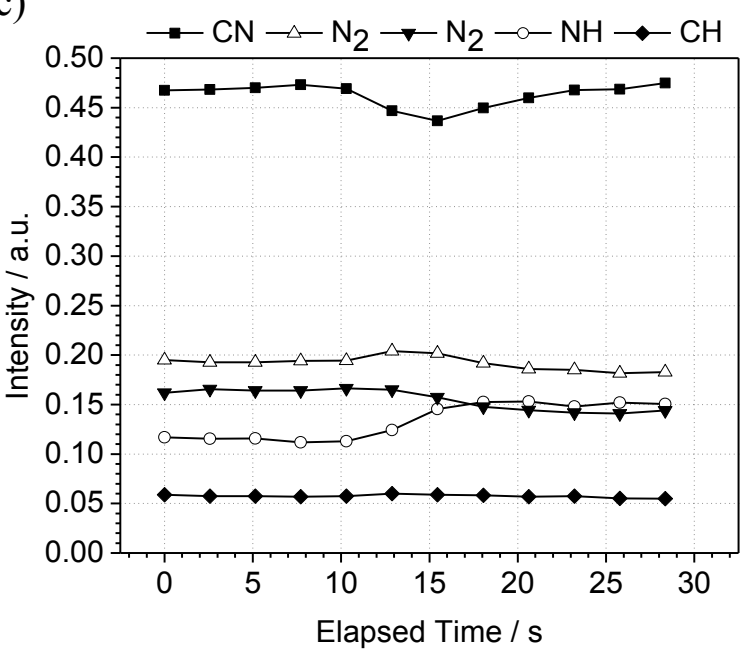

Figure 2. Chemical composition measured in the plasma zone by OES: a) OES spectrum obtained for plasma discharge under the deposition conditions of C-coating, and OES time evolutions of plasmas with a change from conditions b) A to B and c) A to C after $10 \mathrm{~s}$. The data in b) and c) are normalized to the intensity. 


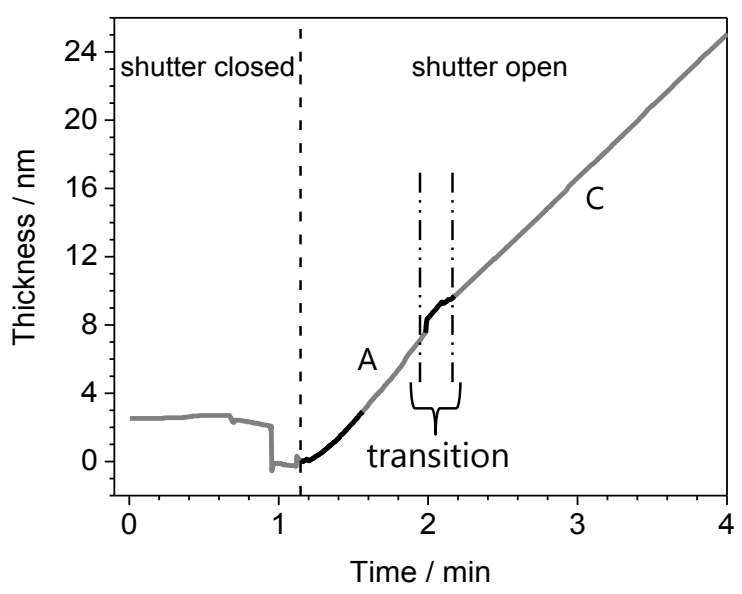

Figure 3. QCM measurements during PPF deposition on Ag-coated quartz crystals showing the coating thickness as a function of time. 


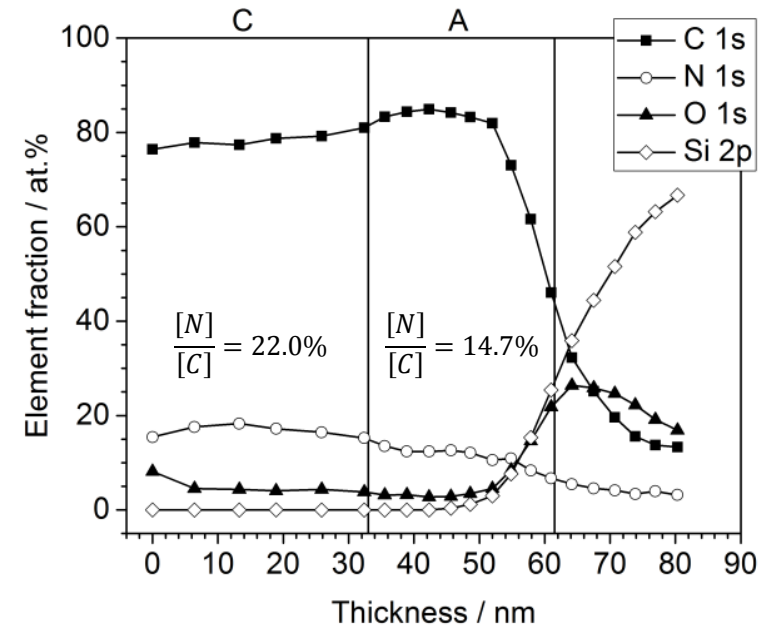

Figure 4. XPS depth profile of an AC-coating deposited on a Si-wafer. 
a)

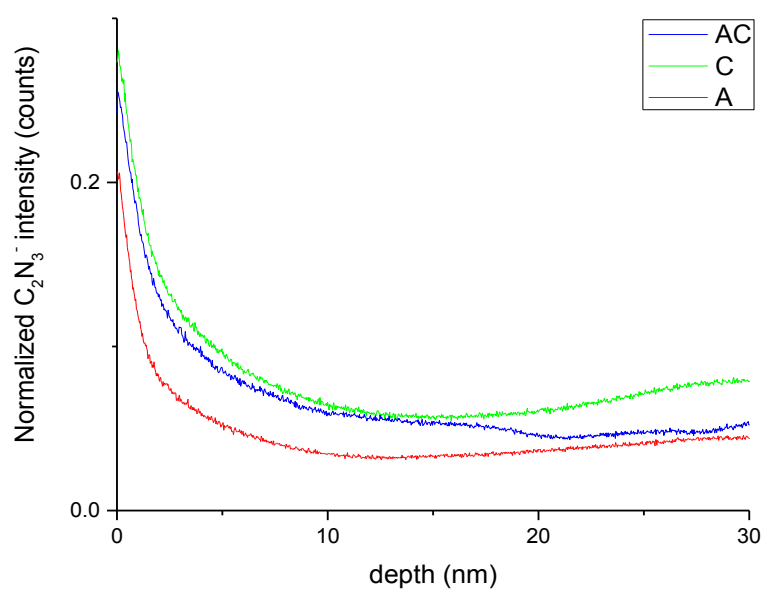

b)

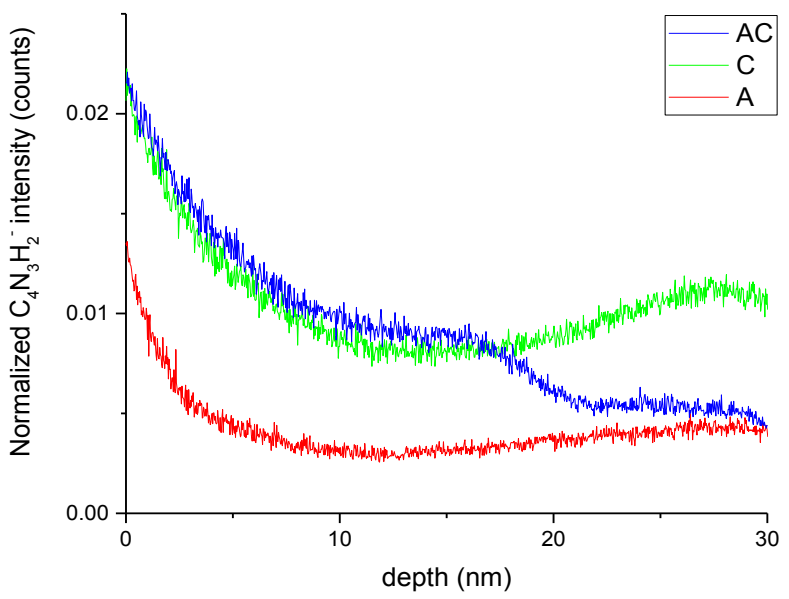

Figure 5. ToF-SIMS depth profiles of the A (red), C (green) and AC (blue) coatings. Evolution of the in-depth concentration of a) $\mathrm{C}_{2} \mathrm{~N}_{3}{ }^{-}$and b) $\mathrm{C}_{4} \mathrm{~N}_{3} \mathrm{H}_{2}{ }^{-}$fragments through the thickness of the coating. 


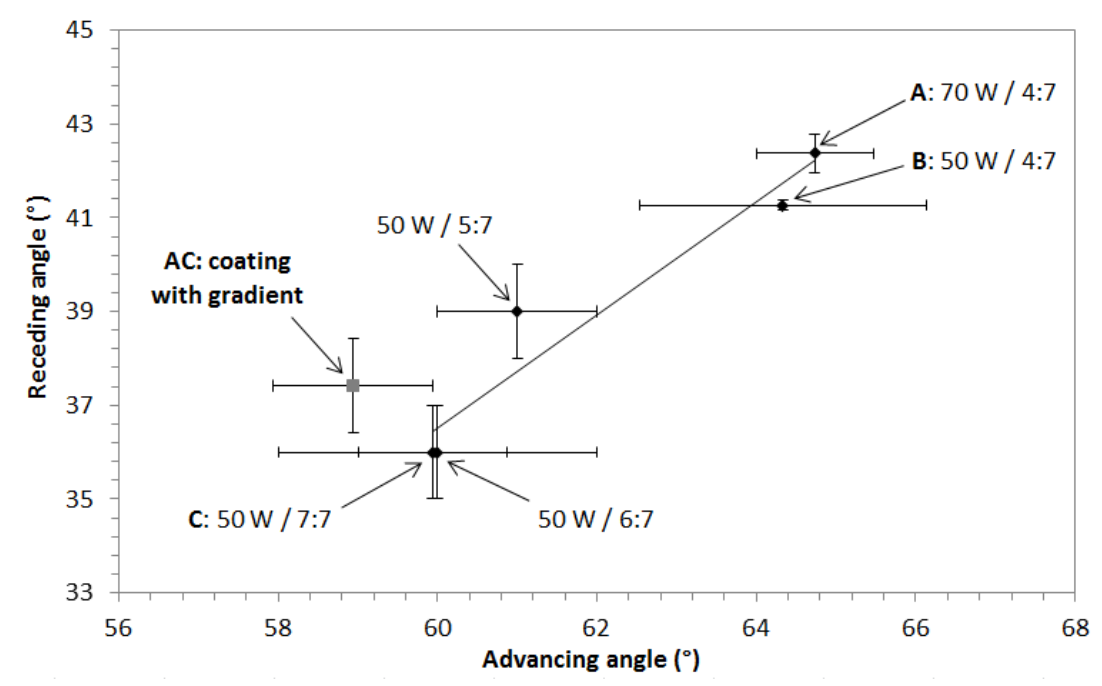

Figure 6. Advancing and receding water contact angle values for single layer PPFs and AC gradient. 

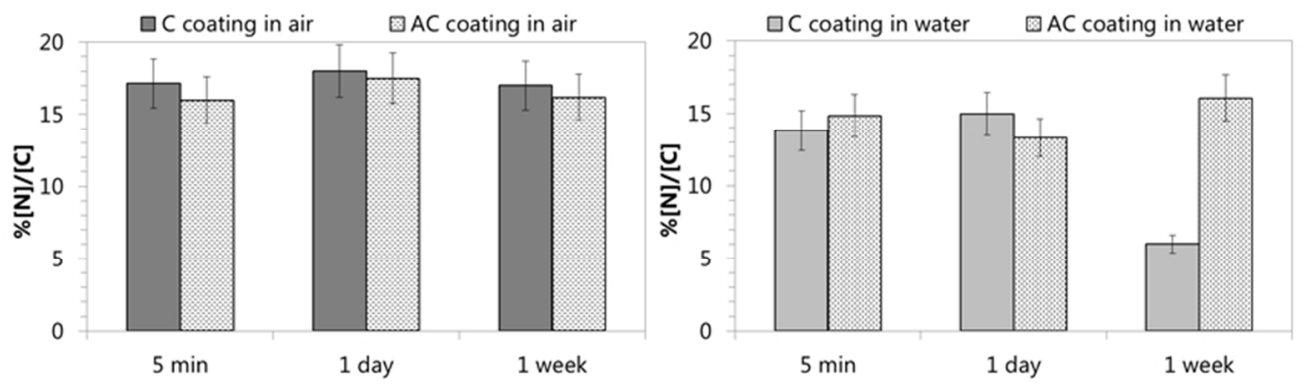

Figure 7. $[\mathrm{N}] /[\mathrm{C}]$ ratios at the surface of single layer $\mathrm{C}$ and gradient AC measured by XPS af-ter 5 min, 1 day or 1 week after deposition and in different aging conditions: a) storage in air and b) storage in distilled water.

$224 \times 66 \mathrm{~mm}(96 \times 96 \mathrm{DPI})$ 


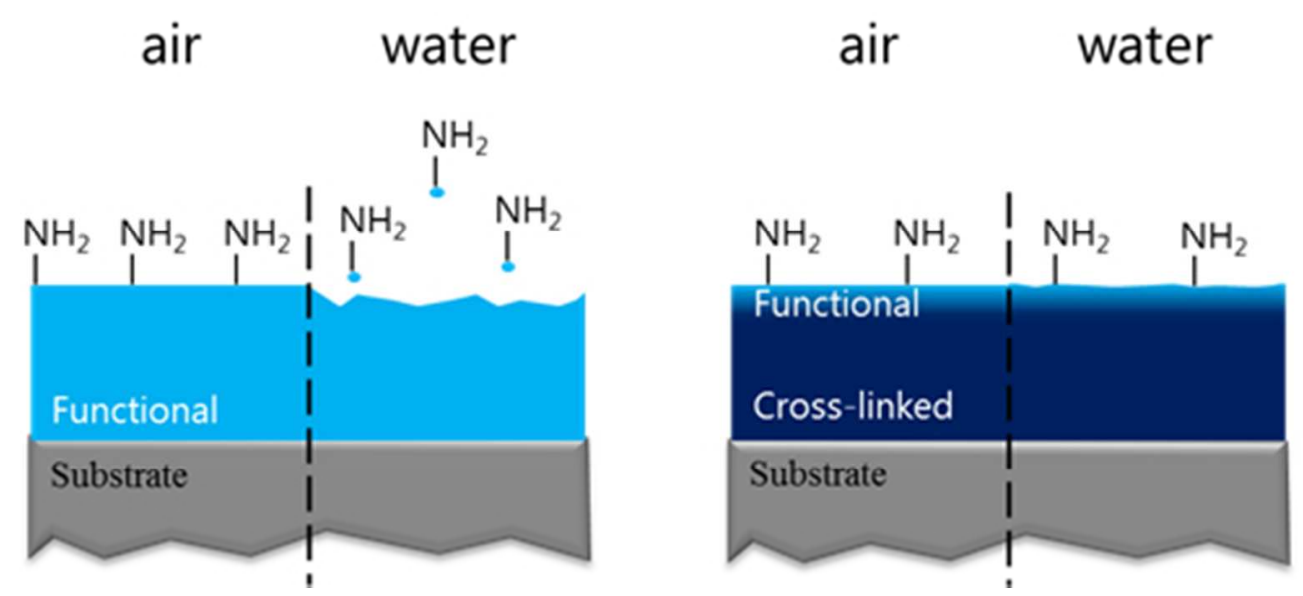

$85 \times 38 \mathrm{~mm}(150 \times 150 \mathrm{DPI})$ 